\title{
Unlocking Sustained Business Value from IT Investments
}

\author{
Joe Peppard \\ John Ward
}

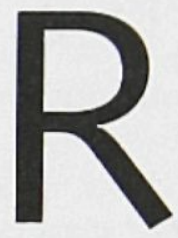

ecently, we were asked by a mid-sized retail financial services institution to assist them in constructing the investment proposal for a new customer relationship management (CRM) system. The need for such a system had been identified during the company's latest IT strategy process. The internal team tasked with developing this proposal had spent the previous four months talking to senior business managers about their requirements and expectations, attending seminars to improve their knowledge in the CRM area as well doing the usual rounds with vendors and undertaking reference site visits. They had also run a series of workshops with key stakeholder groups within the organizations that would be affected by the proposed new system. In finalizing their report to the Board, two issues sat uncomfortably with them. First, the calculated return on investment (ROI) was insufficient to financially justify the investment, particularly as the bank was looking for a quick return. Second, from their conversations with management, they knew that one of the central questions that would be posed by the Board was around the certainty of the benefits they had identified actually being realized-and they had no real answer to this question.

This team's predicament is not uncommon. The issues the team faced are similar to those of any proposed IT investment, particularly those for systems that cut right across the organization. After all the hard work of gathering data, conducting interviews and workshops, putting it all together in a way that makes business sense can often prove difficult, particularly in a climate where "value for money" is the watchword. While the information technology strategy might call for the implementation of a particular application, ensuring that the full business value from this investment is unlocked can be problematic.

We have conducted research over the last five years investigating enterprise systems (ES) implementations, as well as a decade-long study exploring the 
process of unlocking business benefits from IT-enabled initiatives (see Appendix for an overview of the research base). These lessons are valuable in helping firms not only to assess the likelihood of identified benefits actually being realized, but also in building a stronger and more realistic implementation plan. There are many situations where a strong business case has been made for an investment together with a well-considered ROI calculation, yet the business benefits sought never actually materialized, despite the fact that the project was delivered on time, within budget, and met the technical specification.

The benefits to an organization from IT-enabled change essentially emerge from three causes: either stopping doing activities, doing what has always being done but better (i.e., cheaper and/or faster), or doing completely new things. If organizations are to increase the likelihood of success from their IT investments, they must separate out the different sources of the benefits before developing an implementation plan. Approaches to implementation will differ depending on the nature of the change involved. From our data we have identified two distinct types of IT interventions: problem-based implementation and innovation-based implementation. Both are likely to be present in any large-scale IT project, but the impact on employees and other stakeholders will be quite different and the issues that need to be managed will be very dissimilar.

\section{Understanding the Investment Context}

A key characteristic of all enterprise systems (ES) - such as CRM and ERP (enterprise resource planning) - is that they affect a large number of organizational departments and processes, as well as external parties, such as customers or suppliers. Their main differences from more traditional IT developments are the ambitious intentions, the complexity of the application, its cross-functional scope, the range of different stakeholders involved, and the extent of business and organization changes needed to accommodate the new business model inherent in the application. ${ }^{1}$ Furthermore, there is the possibility of bringing the business to a grinding halt if it fails. ${ }^{2}$

Understanding the business context of the investment being considered is critically important. All too often, IT projects quickly become technology projects, rather than primarily business change projects with an IT component, and the context for the investment is soon forgotten. ${ }^{3}$

Joe Peppard is Professor of Information Systems and Director of the Information Systems Research Centre at Cranfield School of Management. <j.peppard@|cranfield.ac.uk>

John Ward is Professor of Strategic Information Systems at Cranfield School of Management and is the co-author of the books Strategic Planning for Information Systems and Benefits Management: Delivering Value from IS \& IT Investments. $<j . m . w a r d @ c r a n f i e l d . a c . u k>$ Although CRM as a software solution is a recent concept, its tenets have been around for some time. Marketers have always promoted building close relationships with customers and providing them with a consistent experience. ${ }^{4} \mathrm{CRM}$ has been difficult to achieve, however, because many companies are organized along product or channel lines rather than the customer ${ }^{5}$-and legacy IT applications have often reinforced this situa- 
tion. CRM is not a product that can be purchased; it is a discipline, a framework, and integrated approach to managing relationships with customers that requires continuous improvement. ${ }^{6}$ It is a strategy, not a tactic; and although supported by IT, it involves considerable organizational re-design, often changing the focus and culture of the organization. ${ }^{7}$ CRM implementation is not easy and the evidence suggests that many companies are struggling with their efforts. ${ }^{8}$

By investing in a CRM system, the bank in the above example was ultimately seeking to reduce costs or increase revenue, ideally both. Its strategy called for "adding value through customer service," increasing customer loyalty, and reducing marketing and sales expenses. Improving customer relationships was to be achieved by improving how the bank deals with the customers, services their accounts, and meets their needs. ${ }^{9}$ Better relationships would then lead to more business being generated from existing customers, a decrease in the number of defecting customers, and a reduction in the overall cost of servicing customers.

However, to achieve these improved relationships, the bank would first have to get to "know" their customers. The bank knew, for example, how many accounts were held at its branches but it did not know how many customers it had-customers could hold multiple accounts in different branches. Since its credit card division was a separate business, they also did not know if a customer with a checking account also had a credit card account. The bank would also have to gain some insight into its customers' needs and preferences so as to be in a position to tailor its products and services to them. Staff would obviously require training to work with this information in their interactions with customers. Finally, there was the not insignificant problem of collecting this information at all points of customer contact.

In business terms, what the bank was attempting to do was clearly not something synonymous with the "quick return" that it was seeking. The two critical issues were: building relationships with customers and increasing understanding and knowledge of customers.

Building relationships with customers is a process not an event. The power in the relationship ultimately lies with the customer because if they are unhappy with the products or level of service they receive, they are very likely to take their business elsewhere. Repeated positive experiences generally lead to a closer relationship and increased loyalty and ultimately generate more business. ${ }^{10}$ Such experiences occur over an extended period of time as the customer and the bank interact with each other-often over many years-although one bad experience can effectively ruin the relationship forever. Consequently, seeking a quick payback is inconsistent with the process of building customer relationships.

Improving understanding of customers requires information, which is used to obtain a more comprehensive picture of the firm's customers. Again, the required information is collected over an extended period of time; no CRM system comes with a database full of customer information. The more information collected, the better the insights, provided the organization has requisite 
capabilities to glean new insights. However, this is often not the case. ${ }^{11}$ The ability to work with information is a crucial aspect of achieving business value. ${ }^{12}$

Operational benefits, particularly process efficiencies and cost savings, generally emerge more rapidly. Responding quickly to customer requests and queries can improve effectiveness as well as contribute to overall customer satisfaction. One Dutch insurance company we studied justified its entire CRM investment based solely on the savings that would be made in its personal injury claims processing. Systems costs can also be reduced by replacing legacy systems, which tend to have a high maintenance cost associated with them. New technologies also tend to be more flexible, opening up future options. ${ }^{13}$

Self-service customer portals can also decrease service costs while improving customer responsiveness. Providing front-line staff with access to customer information directly from their workstations not only improves responsiveness to requests and the quality of their interaction with customers, but also means that the search for information in legacy systems becomes a thing of the past, thereby improving efficiencies. This can also improve employee satisfaction and the impact of this on service quality can be significant. ${ }^{14}$

As with any IT investment, the benefits from implementing CRM software are likely to emerge only if organizational processes are redesigned. This task of reengineering business processes should not be underestimated-as it often is in many ES implementations. The change in work practices that usually accompanies any redesign can result in staff resistance if not managed appropriately. ${ }^{15}$ Many CRM projects fail to deliver the expected return due to their failure to manage the transition. For example, in retail financial services, staff have traditionally serviced accounts or policies not customers. If front-line staff don't accurately capture all customer information, it can undermine the CRM initiative- "garbage in, garbage out" really does hold true.

\section{A Model for Successful ES Implementation}

While ES implementations are major organizational change initiatives, soon after their initiation many default to becoming "software projects." In one survey of ERP projects, $89 \%$ were judged successful-the software worked and the project was delivered close to time and cost forecasts. However, only $25 \%$ had achieved the intended business benefits. ${ }^{16}$ The example in Table 1 summarizes the main reasons for this from the experience of one manufacturing organization. The organization implemented an ES package, from the same vendor, twice. The first time was unsuccessful, but they realized why and had the courage to try again, and this time they succeeded in delivering the expected business benefits.

This company's experience is not unusual-many organizations have reimplementing such systems to gain the benefits that were not achieved the first time. For example, a major pharmaceutical company implemented an ES worldwide in the 1990s across all its manufacturing units, but allowed considerable degrees of freedom to each unit in how it "customized" and utilized the package. 


\section{First Attempt-Failure}

Led by the IT function, with insufficient knowledge of the business functions concerned. Little involvement from other business areas.

Belief that the requirements were simple and already known ("just use the package to automate current processes").

Belief that this was a low-risk and straightforward implementation.

Lack of business buy-in led to the old (mainly manual) system remaining in place with little movement by the business to adopt the new system

Little business or process change: overlaid existing ways of working with the ES. Vendor stressed that the flexibility of the package meant that any changes could be made in the future.

Amendment of package, longer and more complex system build, and difficulty applying upgrades.

\section{Second Attempt-Success}

Led by a newly recruited manager experienced in the business function. Supported from IT function.

Site visits and reviews of other companies' procedures to establish best practice and system requirements.

Knowledge that this would require some major changes.

New procedures completely replaced the previous system and all staff were required to use them (facilities for the old system were withdrawn).

Organizational and business process changes identified and managed from the outset.

Minimal changes to the package and innovative use of built-in facilities. Shorter delivery timescale and easier future upgrade paths

Benefits have exceeded expectations.

As a result, the major supply chain benefits that were expected did not accrue. The re-implementation was more standardized and required all the units to change their practices.

There are several perspectives of ES implementation. In some cases, implementation is seen as a relatively straightforward and low-risk process that can be planned and executed, without incurring significant business or organizational changes. This rarely is the case and is a rather naive view of what is a complex process. ${ }^{17}$ When a management team subscribes to this perspective, the chance of the implementation being a success is severely compromised due to unrealistic understanding of the issues involved. All too often, business problems, constraints, and management and organizational issues cause the implementation to spiral out of control, leading to large time and cost overruns and few, if any, benefits. Ambition does not match the organization's ability to manage the changes associated with the project. The approach followed by the majority of organizations that have been successful with their ES implementations is depicted in Figure 1.

Success often results from a two-phase approach to implementation. ${ }^{18}$ The first phase creates a coherent link between the future business vision and how the ES either shapes that vision or enables it to happen. Not surprisingly, 
FIGURE I. A Model of a Successful Approach to Enterprise System Implementation

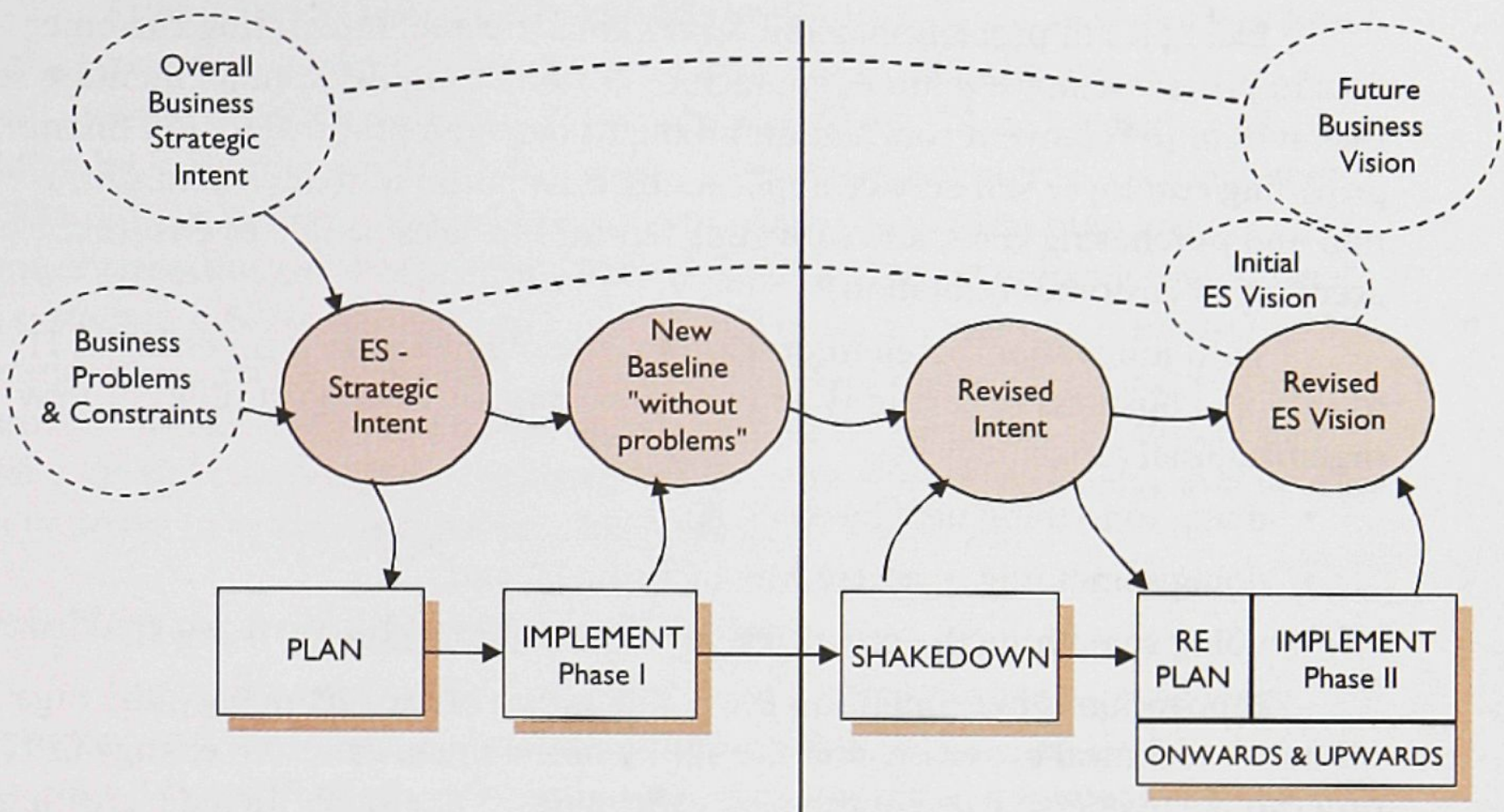

PROBLEM BASED

INNOVATION BASED

the vision is often created by the vendor. Through brochures and glitzy presentations, they describe the idealized future, without any due recognition of where the organization is coming from or what is involved in achieving it. The organization then buys into this vision, believing that it can simply purchase the path to success. While vendors and consultants have a role, the vision must be shaped and owned by the management team.

The first phase establishes an overall vision for how the business will operate once the full benefits of the system are realized, setting an initial intent that delivers a "new baseline" that addresses problems and constraints. Indeed, studies show that business performance often deteriorates immediately after implementation and preventative measures need to be taken-increasing inventories, obtaining additional resources, and informing trading partners of expectations. ${ }^{19}$ The second phase of the implementation focuses on innovation in selected processes and activities. This is where opportunities for competitive advantage through IT are identified. It is crucial to recognize this distinction between problem-based and innovation-based interventions in planning and implementing ES.

With problem-based implementations, the organization is primarily investing in IT in order to:

- overcome an existing disadvantage against competitors,

- prevent performance deterioration, 
- achieve business targets, and

- remove constraints.

Examples of problem-based interventions include: integrating customer data to provide a single point of contact for customer inquiries, implementing an ERP system to remove reconciliation problems between production and finance, providing employee self-service applications via a portal to reduce administration and purchasing costs, and providing lap-tops to sales people to ensure the accuracy of customer quotations.

With innovation-based interventions, the organization is investing in IT to exploit a business opportunity or to create competitive opportunities or new organizational capabilities by:

- doing something new by using IT,

- doing something in a new way by using IT, and

- doing something the organization could not do before by using IT.

Innovation is dependent on the combination of the technology, the organization's technical expertise, and the ability of the organization to change in order to make effective use of the new capabilities. ${ }^{20}$ Examples include: creating an on-line sales channel to reach new customers, introducing vendor managed inventory for key suppliers, allowing customers to do self-billing, deploying a data warehouse and analytics to automate operational decision making, and introducing mobile technologies for professionals to work online during client engagements.

\section{Reconciling the Logic of ES with the Business Vision}

At the start of the initiative, the main issue is how the "vision" of the ES implementation fits with the business vision, with a clear understanding of how the ES implementation contributes to realizing the vision. There are two possibilities:

- The implementation of the ES will provide the new business model on which the vision is based-this generally implies that major business and organizational changes will be needed.

- The business model to achieve the vision is known and the ES is required to make it operational-this implies that there will be trade-offs between the ideal model and the business model embedded in the logic of the ES software.

Most implementations are likely to be a mixture of these two possibilities. Clarity is needed concerning where the ES business model and associated functionality will drive organizational changes. The organization must identify those areas where the organization's business model cannot be compromised, perhaps due to the market advantage that it provides. A cause of some ES implementation failures is that the business model is not understood and the organization adopts processes and systems that do not fit the business model. This will tend 
to produce changes to the ES software during the implementation in order to reproduce the old business model.

Attempting to resolve the current and future business models often highlight a major disconnect between the strategic intent of implementing the system and the resulting actions that must be completed. ${ }^{21}$ One UK bank had difficulty in getting branch staff involved in defining requirements during their CRM project. Senior management's vision of the project was built around customer retention and cross-selling. Branch staff, on the other hand, just wanted a system to process transactions speedily and to get the customer out of the branches as quickly as possible. Getting appropriate engagement and buy-in proved difficult and progress was laborious at times. Yet, after the system had been up and running for a year, staff began to see what was possible and became very active in making suggestions for further development.

\section{Establish the Initial ES Vision and Intent}

As planning commences, the problems and constraints become more apparent and the intent of the implementation has to be scaled back to "a new baseline." It is difficult to put a new vision into operation when engulfed by current problems. ${ }^{22}$ Problem-driven implementation is actually easier to manage than that driven by innovation. It is easier to measure the success; even if the benefits are more limited, they are probably visible soon after implementation. Again, this ability to measure the benefits may reduce the goals to those that can easily be identified, agreed on, and quantified. However, such a compromise may well lead to overall disappointment since the benefits achieved by problem removal rarely justify the expense of an ES.

\section{Shakedown}

With any ES implementation there is inevitably some form of a "shakedown" phase. ${ }^{23}$ This may include resolving serious problems if business performance has been adversely affected, or merely tuning the system and business processes to achieve the expected performance levels. Any implementation should anticipate and plan for this stage, ensuring resources and procedures are in place to deal with the consequences of implementation. During this shakedown phase, a clear understanding must be established of how to optimize performance through further changes to business processes and practices and how further benefits can be achieved through software re-configuration.

This shakedown phase is a pivotal time during the life of any ES project. It is during this phase that there is risk of the project spiraling out of controlsoaking up cash but failing to deliver any benefits-or being abandoned altogether. Performance improvement during this shakedown phase arises from either: internal rationalization of current information (improving its quality); or integration of internal processes and changes to external processes (whether through the creation of new processes or the redesign of current processes). 
TABLE 2. Key Issues in ES Implementation

- To succeed, business models will have to change and so will business and organizational relationships.

- It is the business changes enabled by the ES application that produce the major and lasting business benefits.

- There must be explicitly identified benefits both to the corporation and to the functional units involved in order to enable the business changes. However, implementing an ES system will rarely deliver sufficient immediate benefits to justify the cost and effort. Exploiting the new capability will deliver further benefits.

- Corporate IT initiatives are often distrusted by the business units or functions due to perception of increased centralized control and loss of autonomy.

- The technology is rarely the cause of failure; it is normally the result of organizational issues being unresolved or a poor implementation process.

- ES projects often have an imposed deadline that can seriously affect the likelihood of success. Figure out the requirements of the project first, then determine how long it is likely to accomplish them.

- Poorly defined or ineffectively communicated business vision and strategy will reduce the ES project to a technology project only, owned by the IT function.

- Most organizations realize (after the event) that more resources and expertise should have been dedicated to managing the changes.

\section{Onwards and Upwards}

Once a new or revised intent is established, a new stage of planning and implementation, often in smaller steps, can be carried out. This "onwards and upwards" stage focuses more on innovation and is only feasible in discrete steps, if business risks are to be avoided. ${ }^{24}$ It is important that organizational knowledge gained during the first implementation is retained and transferred to this second phase.

\section{Avoiding a Protracted and Difficult Shakedown Phase}

Implementing an ES is a business transformation program, not merely a technical project. Few fail because of the inadequacies of the technology, but rather because of different perceptions by senior executives, management, and functional units as to the extent of organizational changes. Successful implementations have usually been carefully, even slowly, planned to gain the understanding and commitment of all the stakeholders. Often, two-thirds of the project duration was planning and one-third was implementation. Many failures result from a short planning phase, during which few of the differences in perceptions across stakeholder groups were addressed or reconciled. Table 2 contains a summary of some of the key issues that need to be addressed in relation to ES.

\section{Understanding and Addressing the Different Perspectives that Influence an ES Implementation}

Successful ES implementations involve the management of many diverse interest groups and the adoption of different approaches to the management of project activities and business changes. The different interest or stakeholder 
groups are unlikely to be fixed in their views about what they want and what the ES project can deliver. In reality, people's views tend to adjust as they learn more about the nature of change and how the change affects them and other people.

Within organizations, individual attitudes and perceptions are primarily influenced by four factors:

- Roles and Responsibilities-As a person moves, for example, from middle to senior management role, he or she will need to pay attention to different problems, information, and people when framing problems and making decisions.

- Information Asymmetry-Employees have access to different sources of information about change projects and, consequently, must form their views about a planned change using information of varying completeness, accuracy, and reliability. Never mistake resistance for ignorance that results from lack of communication.

- Professional Background-Inevitably, professional background and expertise have a major bearing on how individuals perceived change. An IT professional, for example, will appreciate an IT project's technical complexity more than an accountant or HR manager.

- Personal Interests - The impacts of a project on personal interests will also affect how the individual perceives a change process. A software engineer, for example, may see a project as an opportunity to develop marketable skills and, consequently, will argue in favor of using novel hardware and software.

These factors, combined with group interests, can result in both individuals and groups having different views of how a project will affect the organization during and after implementation. From a change management perspective, it is particularly important to understand how these factors affect people's perceptions of the resource demands a project will place on the organization and the change effort required for successful implementation.

Typically, the planning of an enterprise systems project often occurs "topdown." Senior management identifies business problems or opportunities they believe will be addressed by an enterprise system. A program or project manager is then appointed to plan and implement an ES project. Finally, line managers and end users are consulted regarding the design and rollout of ES components in their business areas.

In the majority of cases, this top-down approach proves unsatisfactory and project managers find themselves under considerable pressure to complete implementation rapidly, while also receiving demands from users for systems changes. Figure 2 illustrate their contrasting perception of resource demands and the required change effort.

- Senior managers typically have two key concerns: financial performance and ensuring the business will be competitive in the future. They also have limited exposure to the complexities of day-to-day operations. 
FIGURE 2. Diverse Perspectives of Stakeholders: Reaching Consensus

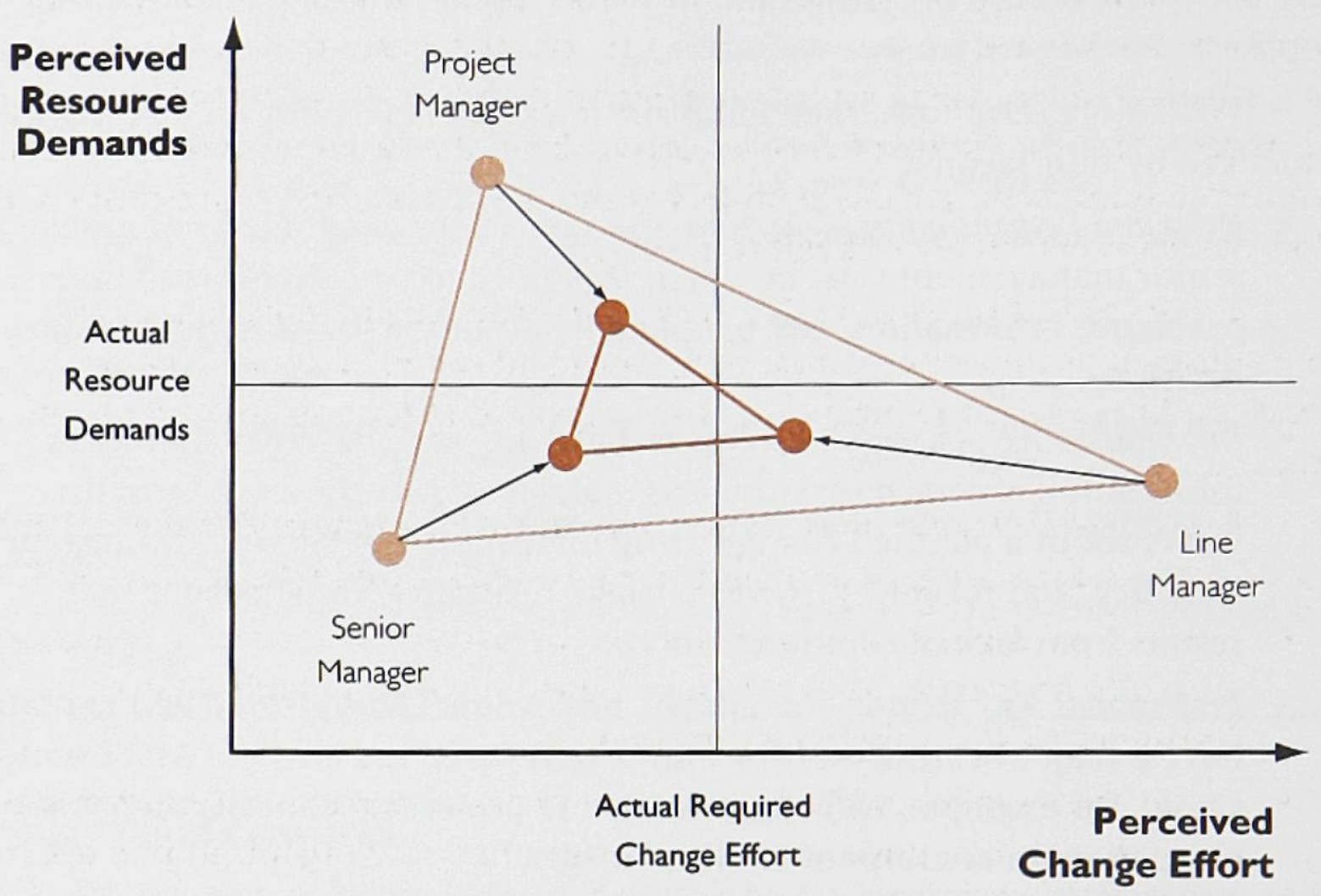

Consequently, they tend to focus on keeping costs and resource usage to a minimum, while having limited understanding of the practical barriers to translating their high-level strategic change plans into reality.

- Project managers appreciate the complexity of large change projects and are more aware of the uncertainty surrounding implementation. As they expect to encounter unforeseen difficulties, they will tend to overestimate resource demands to give themselves a margin for error and to build in some slack. Depending on the professional background of the project manager, his or her initial estimate of the change effort is likely to be relatively low, as project managers will probably not be fully aware of the practical constraints on project implementation, particularly around the people issues. ${ }^{25}$

- Line managers are very familiar with their part of day-to-day operations. Their time is consumed ensuring the business runs smoothly and tackling operational problems as they arise. Any attempts to change operational processes are likely to be seen as increasing their already heavy workload, as well as introducing operational risks. Hence, they often see large change programs, such as ES implementations, as requiring a considerable change effort. However, they usually have little knowledge of the costs of buying, implementing, and operating new information systems until they are made explicit. 
These differences in roles, professional expertise, and personal agendas are likely to cause senior, project, and line managers to have very different perception of ES projects. Even among their ranks, there may be diverse perspectives. The top-down approach to defining ES change places the project manager in a difficult position, being pulled in different directions by different individuals and interest groups. These differences can make it almost impossible for a project manager to implement a change project without encountering significant opposition, which is extremely difficult to resolve.

The introduction of new IT systems can provoke different behaviors (depending on its impact on different groups) and can exacerbate existing behaviors. In essence, the behaviors with respect to IT tend to fall into one of three modes: ${ }^{26}$

- Rational -all stakeholders subscribe to the same organizational goals and focus on achieving those goals through effective and efficient use of IT.

- Trust-a willingness of (some) stakeholders to act in concert to ensure mutually supported goals can be achieved through IT without serious detriment to any stakeholder interest.

- Self-Interest-stakeholders pursue their personal agendas/interests and use IT to protect their positions, often constraining the organizational use or even undermining it.

It is important in an ES implementation to recognize that all three of these modes will exist, probably concurrently, among the stakeholders. While senior managers are more likely to subscribe collectively to the rational view, they have to accept that there will be those who have vested interests to protect and also that existing relationships among some stakeholders are a source of power for either beneficial change or resistance. Existing relationships are likely to be the result of the existing business model, hence the extent of change to the business model caused by the ES is an important consideration-the less change, the more existing relationships are a positive attribute and vice versa.

Each stakeholder-whether an individual, group, or a whole business unit-also needs to be considered in terms of the extent to which they perceive the project producing benefits for them relative to the amount of change they will have to undergo or endure before the benefits are likely to accrue. Some form of resistance can be expected if they perceive that the changes outweigh the benefits or if stakeholders have to endure significant change for no direct benefit. Such resistance could cause major project risks. ${ }^{27}$ Based on the current positioning of each stakeholder and the required level of resources or support they need to provide, an action plan to move their perceptions or deal with their concerns can usually be devised. However, in some cases the gap may be too great and the ambitions for the project should be reduced to enable at least some of the benefits to be realized. Whether substantial additional action is justified or it is better to reduce the investment scope depends on the number and value of the particular benefits that the stakeholder "resistance" may affect. 
It is during the shakedown phase that the impact of changes - shaped and enabled by the IT system on roles and relationships-become apparent. New process designs will inevitably mean changes in work practices and the roles of employees. The consequences and acceptance of these changes dictates the outcome of the shakedown phase. Similarly, new relationships are created and established ones disbanded. New roles and relationships have an inevitable impact on intra-organizational coordination. ${ }^{28}$ These new roles and relationships are often pre-requisites for generating the new thinking essential for innovation, whereas the knowledge required to resolve known problems normally exists in current relationships.

If significant change to the existing business model is required, new trusting stakeholder relationships need to be formed early in the project, based on the business model envisaged. Otherwise, it is likely that-as existing relationships and trust are broken up by the anticipated changes-all the stakeholders will revert to self-protection and self-interest will become the dominant behavior. There are inter-relationships among stakeholders and stakeholder groups that can either be a major enabler or inhibitor of an ES implementation. Figure 3 demonstrates how the modes affect the two-stage approach to implementation:

- At the start of the planning stage an overall rational view of the business and ES models and benefits expected should be behind the process (position "a" in Figure 3), but more detailed planning will normally be affected by existing trust and relationships among stakeholders. What must be avoided is a rapid descent into self-interest when individual stakeholders defend the status quo, normally by adding to the "constraints" (position "b" in Figure 3).

- While the rationale for any changes must be reinforced throughout the project by re-iteration of the benefits, the implementation of the changes will, to a large extent, inevitably be localized. There will be trade-offs made to balance local and shared interests, based on the relationships among the different stakeholder groups.

- Following implementation, the duration and issues encountered in the shakedown phase will be partly dependent on how each stakeholder group has fared in terms of actual and perceived benefits in relation to the changes. If the implementation has not gone well, there is likely to be a period of self-protection and loss of trust, as relationships are stressed. If the new system "doesn't work," the stakeholders at the "sharp-end" (where the business operations can suffer most) are likely to be the most protective to avoid bringing the business "to its knees" for a period (position " $c$ " in Figure 3).

- Before the onwards and upwards innovation stage can proceed, not only does a new rationale for the future vision have to be in place, but also new relationships and trust among key stakeholder groups need to be in place to operationalize the future vision. Protective behaviors based on local interests need to have ceased, either through attention 
FIGURE 3. ES Implementation and Changing Organizational Modes

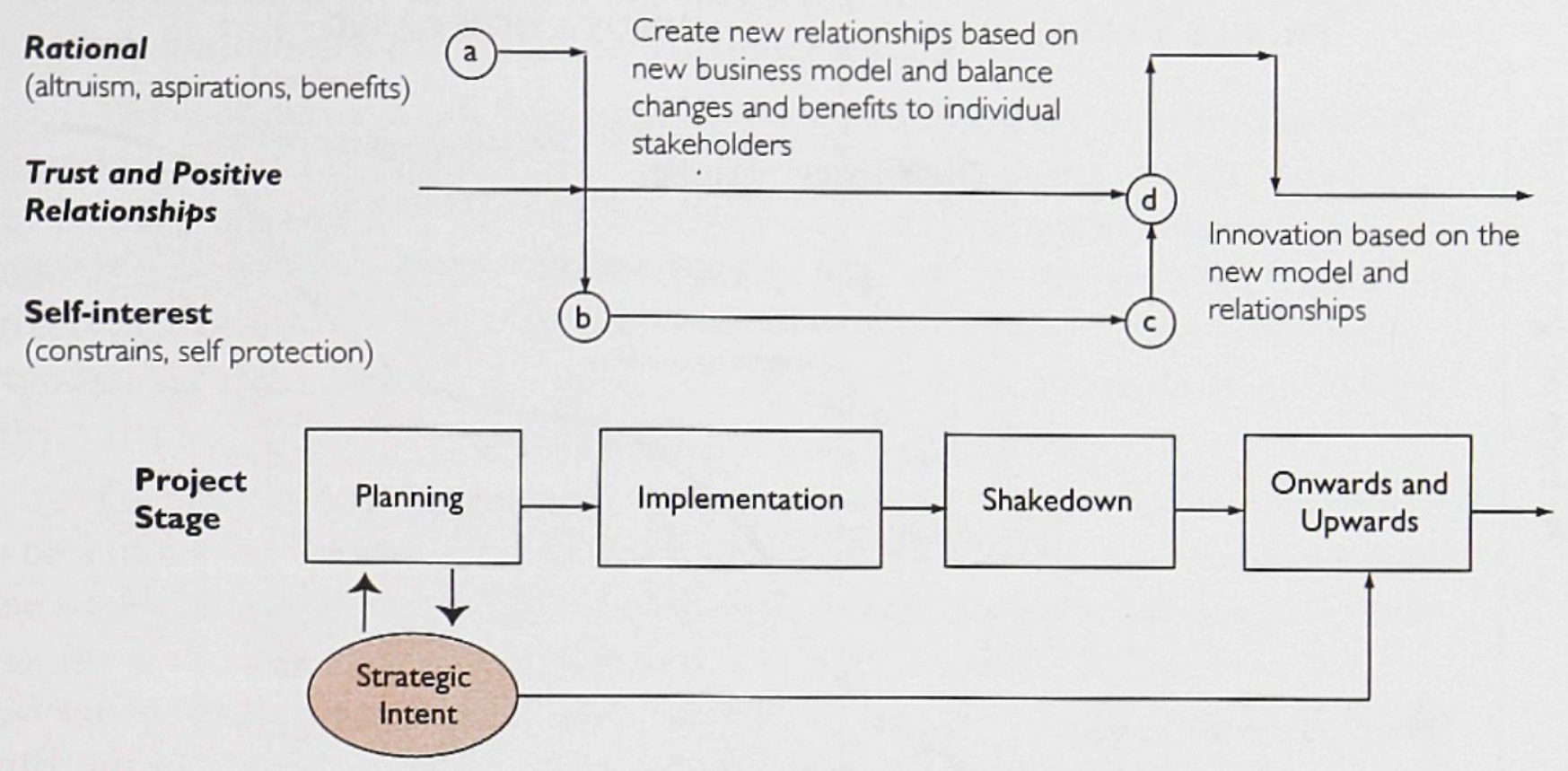

to the specific issues causing the behavior during the shakedown phase or by other compensatory changes to mitigate the negative effects (position "d" in Figure 3).

While all these attitudes will probably exist at the start of the project, how the project is set up in terms of leadership and involvement will have a significant influence on how behaviors evolve. The changes that produce the ES benefits inevitably lead to greater interdependence of business activities by removing the (logically) unnecessary reconciliation and control activities across processes and functional boundaries. The clarity of the business case for the ES, in both operational and strategic terms (i.e., how rational it is) is critical to achieving buy-in both collectively and individually by key stakeholders. However, given the trade-offs that will inevitably be required between different groups in terms of changes and benefits, the degree of trust in existing organizational relationships must be maintained and utilized in defining how the first phase of the implementation will be achieved.

\section{The Two-Phase Approach: Implications for the Return on Investment Curve}

The benefits of an ES do not come all at once when the system goes "live" - as noted, performance often dips in the early days and months. ${ }^{29}$ The nature of the benefits available will vary over the life of the project. For example, our analysis indicates that the ROI curve for CRM shows little return in the early days of the investment. However, over a period of several years, through increasing customer insight and improving relationships, the payback can be 
FIGURE 4. The Return on Investment Curve: An Example from a CRM Implementation

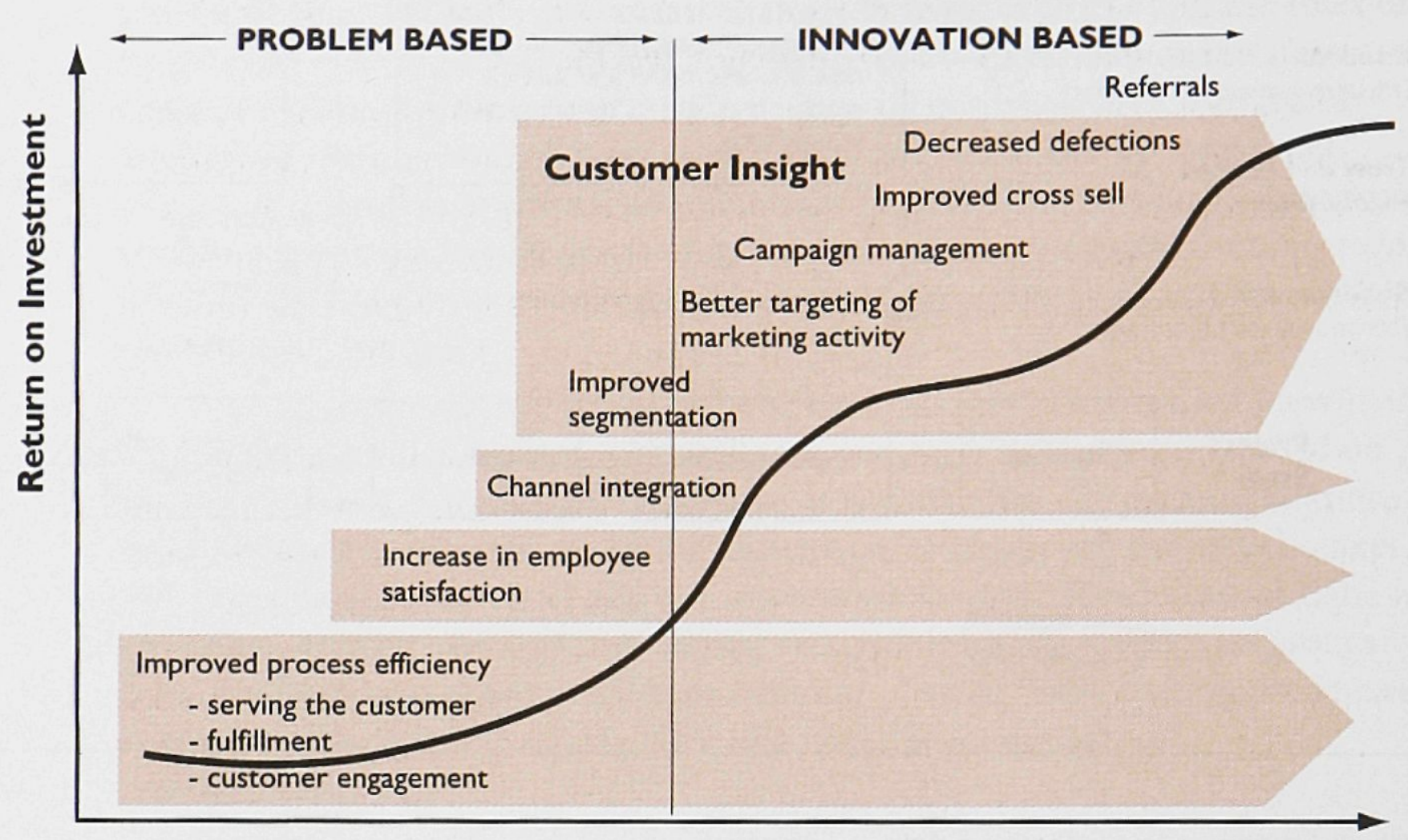

Time

significant. This curve should be considered in putting together any investment proposal for any ES.

Figure 4 illustrates the generic profile of the curve for a CRM implementation-it will vary from organization to organization, influenced not least because of their differing starting positions. In the early days and months of the program, benefits are likely to be as a result of solving current problems, generally improving efficiencies and improving information quality. For example, in an insurance company we studied, mobile sales agents were an important distribution channel but were acting as an information sieve. The agents had direct access to a rich source of customer details, but neglected to communicate much of this information to the headquarters, call center, and other back-office functions. A promise from them to deliver more information on a product or fresh leads generated while with a client was often forgotten, as there was not a mechanism in place to capture and route this information to appropriate departments. However, through the implementation of sales force automation, the sales force could share information with others in the organization, solving a problem that had long plagued them. They have now created a revised vision for CRM that is more innovation-based and focuses more on the customer rather than on solving an organizational problem.

Once current problems have been addressed, innovation-based activity can be undertaken, which can result in significant returns. For example, with improvements in customer information, market segmentation can be improved, 
propensity to purchasing modeling undertaken, and marketing activity more focused. One UK bank saw its response rates for marketing campaigns increase from $2 \%$ to more than $40 \%$-but this was 3 years after it first began its CRM initiative. It attributed this to greater customer insight.

These arguments call into question the figures that are continually tossed around regarding the failure rate of CRM. For example, industry analysts Gartner calculate that $65 \%$ of CRM projects failed in $2001 .{ }^{30}$ In assessing such findings it is important to consider the timeframe over which the so-called "failed" projects are being assessed. It might just be that within a short time-scale the expected benefits were not delivered-but as pointed out above, how could they be?

One particular life assurance company assessed its CRM implementation to be a moderate success when it first introduced it five years ago, and indeed at one stage considered replacing it. A post-implementation ROI analysis indicated that the investment was showing little return compared to the figures in the investment proposal. Recently, however, they were voted "best company to deal with" in a nationwide survey of brokers, its principal channel to market. Income has increased threefold over the last two years and the level of expense incurred to service this business has also been reduced dramatically. Further evidence is provided by the Britannia Building Society, who in 2002 scooped up an award for best CRM implementation in financial services. While it is now receiving accolades, the Society in fact began its CRM initiative all the way back in $1995 .{ }^{31}$

\section{Realizing Value: A Journey Not a Destination}

The issues faced by the bank, as outlined in the beginning of this article, involve recognizing that CRM is a long-term investment in both business and technical terms. It is not only about building a customer knowledge base for the organization to exploit, but also about building listening and responding mechanisms and sharing some of the value derived from that information with the customer. Often, its success depends on customers changing their behaviors. In short, expecting a quick payback is inconsistent with the requirements necessary for successfully building relationships with customers. The investment must therefore be assessed in this light; unfortunately few are. It may be that conventional approaches to calculating ROI are inappropriate for expressing expected returns and providing the justification for investments in IT.

Furthermore, organizations must continually work to achieve benefits and this requires the active engagement and involvement of both business management and users. This requires the construction of a benefits realization plan, detailing the source of the benefits, responsibilities for making changes, and timescales for achievement. ${ }^{32}$ An ES implementation is, in essence, a significant organizational change initiative and any such intervention is best viewed as a two-phase process, which emphasizes the critical importance of managing through the "shakedown" phase of the project. Approaches to implementation will differ depending on whether the intervention is problem-based 
or innovation-based. Failure to recognize this distinction may mean that any value realized will be sub-optimal. Finally, realizing value is a journey not a destination.

\section{APPENDIX}

\section{About the Research}

This article is based on three related research projects conducted the Information Systems Research Centre at Cranfield School of Management.

The first is a longitudinal study that has explored how organizations can unlock business benefits and value from their investments in IT. The researchers worked with companies including Alliance \& Leicester, AstraZeneca, The NatWest Bank, GlaxoSmithKline, British Energy, and British Telecom. The key findings of the study can be found in John Ward and Joe Peppard, Strategic Planning for Information Systems, 3rd Edition (Chichester: John Wiley and Sons, 2002) and John Ward and Elizabeth Daniel, Benefits Management: Delivering Value from IS and IT Investments (Chichester: John Wiley and Sons, 2005).

The second is a study of CRM projects in a variety of different organizations. Case studies were undertaken in 15 companies: Canada Life, Orange, Derbyshire Building Society, Britannia Building Society, The NatWest Bank, Friends First, Homebase, Reaal Particulier, Electrocomponents, Siemens, Nortel Networks, Sears, Roebuck and Company, Aserta Homes, Wesleyan Assurance Society, and Sun Microsystems. The findings of this study have been published in Simon Knox, Stan Maklan, Adrian Payne, Joe Peppard, and Lynette Ryals, Customer Relationship Management: Perspectives from the Marketplace (Oxford: Butterworth-Heinemann, 2003).

The third project is a study of the particular change and organizational issues associated with the successful deployment of enterprise systems. The scope of the project included all types of enterprise-wide systems. In-depth case studies were undertaken in AstraZeneca, Qinetiq (formerly the UK's Defense Establishment Research Agency), Electrocomponents, and Mitel. The findings are published in J. Ward, C. Hemingway, and E. Daniel, "A Framework for Addressing the Organizational Issues of Enterprise System Implementation," Journal of Strategic Information Systems (2005).

\section{Notes}

1. This business model is the business logic that is embedded in the software.

2. Over the years there have been a number of high-profile cases involving organizations claiming that their ES severely impacted their business. On occasions, the impact was so detrimental that a number of organizations even filed for bankruptcy. For example, FoxMeyer Drug, a \$5 billion wholesale drug company filed for Chapter 11, at least in part because of problems with its ERP implementation. Avis Europe took an exceptional charge of $£ 40-45$ million related to its decision to scrap its deployment of a new ERP system due to cost overruns and delays. See J. Scott, "The FoxMeyer Drugs' Bankruptcy: Is It a Failure of ERP?" in Proceedings of the Association of Information Systems Fifth Americas Conference on Information Systems, Milwaukee, WI, August 1999; "Avis Europe Is Latest to Get Stung by IT," Computer Weekly, October 25, 2004. 
3. See L. Markus, "Technochange Management: Using IT to Drive Organizational Change," Journal of Information Technology, 19/1 (2004): 4-20; R. Kohli and S. Devaraj, "Realizing the Business Value of Information Technology Investments: An Organizational Process," MIS Quarterly Executive, 3/1 (2004): 53-68. Davenport noted that "successful implementation of ES does involve probably the greatest technological change most organizations have ever undergone....Even more difficult and important, however, are the major changes in business that come with an ES project" (pp. 5-6). See T.H. Davenport, Mission Critical: Realizing the Promise of Enterprise Systems (Boston, MA: Harvard Business School Press, 2000). In relation to Nestlé USA's experience with ES, Chief Information Officer Jeri Dunn was recently quoted as saying "no major software implementation is really about software," CIO Magazine, 15 (May 2002).

4. See, for example, B.B. Jackson, "Build Customer Relationships that Last," Harvard Business Review, $63 / 6$ (November/December 1985): 120-128; E. Gummesson, "The New MarketingDeveloping Long Term Interactive Relationships," Long Range Planning, 20/4 (August 1987): 10-20; M.G. Christopher, A.F. Payne, and D. Ballantyne, Relationship Marketing: Bringing Quality, Customer Service and Marketing Together (Oxford: Butterworth-Heinemann, 1991).

5. M. McDonald and I. Dunbar, Market Segmentation: How to Do It, How to Profit From It, 2nd Edition (Houndmills: Macmillan, 1998).

6. B.J. Pine, Mass Customization: The New Frontier in Business Competition (Boston, MA: Harvard Business School Press, 1993).

7. See S. Knox, S. Maklan, A. Payne, J. Peppard, and L. Ryals, Customer Relationship Management: Perspectives from the Marketplace (Oxford: Butterworth-Heinemann, 2003); A. Agarwal, D.P. Harding, and J.R. Schumacher, "Organizing for CRM," McKinsey Quarterly, 3 (2004): 80-91.

8. D.K. Rigby, F.F. Reichheld, and P. Schefter, "Avoid the Four Perils of CRM," Harvard Business Review, 80/2 (February 2002): 101-109; N. Woodcock and M. Starky, "I Wouldn't Start from Here: Finding a Way to CRM Projects," Journal of Database Marketing, 9/1 (2001): 61-74; D.L Goodhue, B.H. Wixom, and H.J. Watson, "Realizing Business Benefits through CRM: Hitting the Right Target in the Right Way," MIS Quarterly Executive, 1/2 (2002): 79-94.

9. V. Zeithaml, A. Parasuraman, and L.L. Berry, Delivering Quality Service: Balancing Customer Perceptions and Expectations (New York, NY: The Free Press, 1990); J.L. Heskett, W.E. Sasser, and L.A. Schlesinger, The Service Profit Chain: How Leading Companies Link Profit and Growth to Loyalty, Satisfaction, and Value (New York, NY: The Free Press, 1997).

10. Christopher et al., op. cit.

11. This observation has also been made by others. See T.H. Davenport, J.G. Harris, D.W. Delong, and A.L. Jacobson, "Data to Knowledge to Results: Building an Analytic Capability," California Management Review, 43/2 (Winter 2001): 117-138; D.A. Marchand, W. Kettinger, and J.D. Rollins, "Information Orientation: People, Technology and Bottom Line," Sloan Management Review, $41 / 4$ (Summer 2000): 69-80.

12. S. Devaraj and R. Kohli, "Performance Impacts of Information Technology: Is Actual Usage the Missing Link?" Management Science, $49 / 3$ (March 2003): 273-289.

13. It is for this very reason that a number of scholars have been proposing "real options" as providing an approach to justifying investments in information technology. An option is a right but not an obligation to do something in the future. See Y.J. Kim and G.L. Sanders, "Strategic Actions in Information Technology Investment Based on Real Option Theory," Decision Support Systems, 33/1 (May 2002): 1-11; A. Taudes, "Software Growth Options," Journal of Management Information Systems, 15/1 (Summer 1998): 165-185; M. Benaroch and R.J. Kauffman, “A Case for Using Real Option Pricing Analysis to Evaluate Information Technology Project Investments," Information Systems Research, 10/1 (March 1999): 70-86; A. Kambil, J.C. Henderson, and H. Mohsenzadeh, "Strategic Management of Information Technology: An Options Perspective," in R.D. Banker, R.J. Kauffman, and M.A. Mahmood, eds., Strategic Information Technology Management: Perspectives on Organizational Growth and Competitive Advantage (Harrisburg, PA: Idea Group Publishing, 1993).

14. Heskett et al., op. cit.

15. J. Peppard and P. Rowland, The Essence of Business Process Re-engineering (Hertfordshire: Prentice-Hall, 1995).

16. "Achieving the Benefits From Software Package Enabled Business Improvement Programmes: Best Practice Guidelines," The IMPACT Programme Ltd., London, 1998.

17. E.J. Umble, R.R. Haft, and M.M. Umble, "Enterprise Resource Planning: Implementation Procedures and Critical Success Factors," European Journal of Operational Research, 146/2 
(2003): 241-257; C. Francalanci, "Predicting the Implementation Effort of ERP Projects: Empirical Evidence on SAP/R3," Journal of Information Technology, 16/1 (March 2001): 33-48; M. Sumner, "Risk Factors in Enterprise-Wide/ERP Projects," Journal of Information Technology, 15/4 (December 2000): 317-327.

18. "ERP's Second Wave: Maximizing The Value of ERP Processes," Deloitte Consulting, London, 1998; M.L. Markus, S. Axline, D. Petrie, and C. Tanis, "Learning from Adopters' Experiences with ERP: Problems Encountered and Success Achieved," Journal of Information Technology, 15/4 (December 2000): 245-265; The IMPACT Programme Ltd., op. cit.

19. J.W. Ross and M.R. Vitale, "The ERP Revolution: Surviving vs. Thriving," Information Systems Frontiers, $2 / 2$ (August 2002): 233-241; Markus et al., op. cit.; The IMPACT Programme Ltd., op. cit.

20. This has been referred to as "technochange." See Markus, op. cit.

21. N.H. Bancroft, H. Seip, and A. Sprengel, Implementing SAP R/3: How to Introduce a Large System into a Large Organization, 2nd Edition (Greenwich, CT: Manning Publications,).

22. Markus et al., op. cit.

23. The concept of the "shakedown" phase has been coined by Markus et al., op. cit.

24. For a recent analysis of IT project risk see C.F. Gibson, "IT-Enabled Business Change: An Approach to Understanding and Managing Risk," MIS Quarterly Executive, 2/2 (September 2003); "The Challenges of Complex IT Projects," The Royal Academy of Engineering, London, 2003.

25. A similar observation was made by Markus regarding the training and education of project managers. See Markus, op. cit.

26. This assessment is based on the work of Kumar et al. While the literature identified two extreme modes of behavior, rationalism and segmented institutionalism, they identified relationships and trust. This accepts that different stakeholders will have different interests but some existing relationships of mutual trust among stakeholders enables some agreement to be reached within a rational overall approach. See K. Kumar, H.G. van Dissel, and P. Bielli, "The Merchant of Prato-Revisited: Toward a Third Rationality of Information Systems," MIS Quarterly, 22/2 (June 1998): 199-226.

27. It is not the intention of this article to discuss risk analysis. In a recent paper, Gibson identified three factors determining business change risk: leadership of the change; employees' perspectives on the change; and scope and urgency of the change. See Gibson, op. cit.

28. Research suggests that intra-organizational coordination after system implementation is imperative for value-flows. See A. Barua, C.H.S. Lee, and A.B. Whinston, "The Calculus of Reengineering," Information Systems Research, $7 / 4$ (December 1996): 409-428; B.J. Bashein, M.L. Markus, and P. Riley, "Preconditions for BPR Success, and How to Prevent Failures," Information Systems Management, 11/2 (Spring 1994): 7-13.

29. This has been referred to as the IT value latency problem. See K.H. Goh and R.J. Kauffman, "Towards a Theory of Value Latency for IT Investments," paper presented at the 38th Hawaii International Conference on Systems Science, January 2005.

30. "Moving from Disillusionment to Real Value: An Introduction to the Eight Building Blocks of CRM," Gartner Group CRM Conference, Paris, May 2002.

31. A fuller treatment of the Britannia Building Society can be found in Knox et al., op. cit.

32. For an approach to benefits realization planning, see J. Ward and E. Daniel, Benefits Management: Delivering Value from IS and IT Investments (Chichester: John Wiley and Sons, 2005). 
Copyright of California Management Review is the property of California Management Review and its content may not be copied or emailed to multiple sites or posted to a listserv without the copyright holder's express written permission. However, users may print, download, or email articles for individual use. 